\title{
The Analysis of Garden Path Phenomenon from Transitivity in SFL
}

\author{
Wei Zhang, Yao Zhao*, Shanshan Wang \\ Foreign Languages College, Beihua University, Jilin 132013, China
}

Keywords: Systemic Functional Linguistics, Transitivity, Garden Path Phenomenon

\begin{abstract}
Garden Path Phenomenon (GPP), proposed by Bever (1970), is one of the most widely discussed topics concerning different types of ambiguities and it has been studied from aspects of semantics, pragmatics, psycholinguistics and cognitive linguistics, etc for the last four and a half decades throughout the world. Systemic Functional Linguistics, proposed by M.A.K. Halliday (1985), is a general linguistics theory which is said to be able to explain all kinds of language phenomena. Hence, in this paper, GPP will be analyzed from one subsystem of SFL-Transitivity System to demonstrate that SFL is a workable approach to the study of GPP.
\end{abstract}

\section{Introduction}

As a human language phenomenon, GPP can be found in language comprehension, which refers to the fact that a language user initially mis-analyzes a syntactic ambiguity and later has to correct it at some cost (Frazier, 1987). That is to say, when comprehending a certain type of sentence, people have a strong tendency of misinterpreting the sentence at first and finally have to backtrack in rereading it and construct another interpretation. The studies on Garden Path Phenomenon can be traced back to the 1970s. In the1970s, the studies on GPP were mainly concentrated on the field of psycholinguistics. In the 1980s, the studies on GPP extended to the fields of psycholinguistics, cognitive linguistics as well as pragmatics. In the 1990s, this phenomenon began to be researched via grammatical analysis. In the 2000s, the studies in this field were mainly focused on semantics. However, no research has been made to analyze GPP from the perspective of systemic functional linguistics. Therefore, a tentative study of GPP from one subsystem of SFL-the Transitivity system - will be conducted to prove that SFL is also a workable approach to the study this phenomenon.

\section{Garden Path Phenomenon}

In 1970, American psycholinguist T. G. Bever created his first classical example of GP sentence The horse raced past the barn fell, which has aroused immense attention among scholars (Pritchett, 1988; Fodor \& Inoue, 1990; Jiang Zukang, 2000) and led to one of the hottest topics in psycholinguistics, namely the GPP. The processing of such types of sentences is much like walking in the garden, when the sightseers walk down the usual path, they suddenly find that they are walking in a wrong way and have to come back to the place where they started to walk. The term "garden path" has been thus vividly explained and described. Different researchers have given different names to this phenomenon, such as "temporary ambiguity" (Frazier and Rayner, 1982:178), "local ambiguity” (Pritchett, 1988:540) and “potential ambiguity” (Feng Zhiwei \& Xu Fuji, 2003)

\section{Systemic Functional Linguistics and Transitivity System}

Systemic Functional Linguistics (SFL) has been introduced and developed by Halliday on the basis of Firth's theories. His SFL is a sociologically oriented functional linguistic approach and one of the most influential linguistic theories in the twentieth century. SFL has two components: Systemic grammar and Functional grammar. They are two inseparable parts for an integral framework of linguistic theory. Systemic grammar aims to explain the internal relations in language as a system network, or meaning potential. And this network consists of subsystems from which language users make choices. Functional grammar aims to reveal that language is a means of social 
interaction, based on the position that language system and the forms that make it up are inescapably determined by the uses or functions which they serve. In Systemic Grammar, the notion of system is made of a central explanatory principle, the whole of language being conceived as a "system of systems". Systemic Grammar is concerned with establishing a network of systems of relationships, which accounts for all the semantically relevant choices in the language as a whole. According to Halliday (1985), adult language has three metafunctions: the ideational function, the interpersonal function and the textual function. Specifically speaking, the ideational function is realized by transitivity system, the interpersonal function by the mood system and the textual function is realized by thematic system.

Halliday (1970) makes the statement that the ideational function is realized by Transitivity, Voice as well as Polarity. Transitivity is simply the grammar of the clause in its ideational aspect. It consists of six different processes: Material Process, Behavioral Process, Mental Process, Verbal Process, Relational Process, and Existential Process. The material process is the process of doing with two participants, "Actor" and "Goal". The mental process is a process of sensing which expresses perception, reaction, and cognition, with two participants "Sensor" and "Phenomenon". The relational process is a process of being which reflects the relationship between two entities. The relational process can be classified into two types: Attributive and Identifying, with the former expressing what attributes a certain object has or what type it belongs to and the latter expressing the identical properties of two entities. These two relations can be further classified into Intensive, Circumstantial, and Possessive. The behavioral process is a process of behaving, such as breathing, sighing crying, dreaming, laughing and so forth with only one participant "Behaver". The verbal process is a process of saying with three participants "Sayer", "Receiver" and "Verbiage". The existential process is a process of existing with one participant "Existent".

\section{The Analysis of Garden Path Phenomenon from Transitivity in SFL}

Based on the previous statement of GPP and Transitivity in SFL, this part will be focused on the analysis of GPP from the perspective of transitivity. The selected GPP Clauses will be analyzed according to their different processes, participants as well as circumstantial elements. The classical clause of GPP will be analyzed first.

(1)The horse raced past the barn fell

At the first sight of this clause, the analysis can be conducted in the following:

\begin{tabular}{|c|c|c|c|}
\hline The horse & raced & past the barn & fell \\
\hline Actor & Material Process & Circumstance & Goal? \\
\hline
\end{tabular}

From the first analysis, it is obvious that this clause is a material process, with the horse as the Actor, raced as the Material Process and past the barn as the Circumstance. However, the function of fell is puzzling in this material process. According to the material process, the missing constituent in this clause should be a Goal. According to Halliday, Goal should be realized by a nominal group, but the word fell is a verb, which can be another material process and this clause is not the clause complex and there is no conjunctives to connect two processes. Thus this kind of analysis is not correct and has to be reconsidered. After reconsideration, the analysis can be done in the following:

\begin{tabular}{|c|c|}
\hline The horse raced past the barn & fell \\
\hline Actor & material Process \\
\hline
\end{tabular}

In this analysis, the material process is realized by the verb fell, and the actor is realized by the nominal group complex with an embedded non-finite clause. Such a comprehension can interpret GPP in a clear way. Thus the correct location of the process is first method to interpret GPP Clauses. The second clause also involves the process.

(2)The girl told the story cried.

The typical analysis of the second example will go as follows:

\begin{tabular}{|c|c|c|c|}
\hline The girl & told & the story & cried \\
\hline
\end{tabular}




\begin{tabular}{|c|c|c|c|}
\hline Sayer & Verbal Process & Verbiage & Receiver? \\
\hline
\end{tabular}

At the first comprehension of this clause, it can be regarded as a verbal process. The process is realized by the verb told, with the girl as the Sayer and the story as the Verbiage. However, the word cried can only be the realization of Receiver, which is incorrect because Receiver can only be realized by the nominal group and the word cried is a verb. Thus this kind of analysis is not correct and has to be reconsidered. After reconsideration, the analysis can be done in the following:

\begin{tabular}{|c|c|}
\hline The girl told the story & cried \\
\hline Behaver & Behavioral Process \\
\hline
\end{tabular}

This time, the whole clause can be analyzed as a Behavioral process, with the process realized by the verb cried and the Behaver realized by the nominal group complex with an embedded non-finite clause. From the above analysis, it can be concluded that the correct choice of the process can solve the problem of GPP. The third example and the fourth example involve the correct choice of participants.

(3)I told the girl that I met a story.

(4)I convinced her boys are naughty.

In example 3, the clause can be normally analyzed in the following way.

\begin{tabular}{|c|c|c|c|c|c|c|}
\hline I & told & the girl & that & I & met & a story \\
\hline Sayer & Verbal Process & Receiver & \multicolumn{5}{|c|}{ Verbiage } \\
\hline \multicolumn{3}{|l|}{} & & Actor & Material Process & Goal? \\
\hline
\end{tabular}

It is obvious that this clause is a verbal process, with the process realized by the verb told, the Sayer by $I$, the receiver is realized by the nominal group the girl and the verbiage is realized by another clause. In the second clause, it is a material process with the process realized by the verb met, the Actor by $I$ and the Goal by the nominal group $a$ story. However, the goal is usually realized by the nominal group indicating a person or a thing, but $a$ story is an entity. Thus it can not be a goal. Therefore this kind of analysis is not correct and has to be reconsidered. The nominal group $a$ story is more likely related to the verb told, thus the following analysis can be concluded:

\begin{tabular}{|c|c|c|c|}
\hline I & told & the girl that I met & a story \\
\hline Sayer & Verbal Process & Receiver & Verbiage \\
\hline
\end{tabular}

In such an analysis, this clause is also a verbal process with the same Sayer and the same Process. However, the Verbiage is realized by the nominal group a story and the Receiver is realized by the nominal group complex with an embedded finite clause. Such an analysis can make this clause comprehensible. Thus, the correct location of the right participants can provide a better understanding of GPP. Example 4 is the same with Example 3. At the first glance, Example 4 can be analyzed as follows:

\begin{tabular}{|c|c|c|c|}
\hline I & convinced & her boys & are naughty \\
\hline Sayer & Verbal Process & Receiver & Verbiage? \\
\hline
\end{tabular}

It is apparent that this clause is a Verbal process with the process realized by the verb convinced, the Sayer by I, the Receiver by the nominal group her boys. However, are naughty can not be a verbiage because the verbiage is usually realized by a nominal group or a clause. After reconsidering the realization of the participants, the correct analysis will be conducted in the following:

\begin{tabular}{|c|c|c|c|}
\hline I & convinced & her & boys are naughty \\
\hline Sayer & Verbal Process & Receiver & Verbiage \\
\hline
\end{tabular}

With the changed realization of the Receiver and the Verbiage, this GPP clause can be easily understood, which can prove that the correct location of the right participants can provide a better understanding of GPP. The last example involves the circumstance element.

(5)Without her contributions would be impossible.

When this example is analyzed, it is obvious that it is a Relational process, which can be initially analyzed in the following: 


\begin{tabular}{|c|c|c|c|}
\hline Without her contributions & ? & would be & impossible \\
\hline Circumstance & Carrier? & Relational Process & Attribute \\
\hline
\end{tabular}

This relational process thus analyzed poses a problem in which there is only one entity in this clause realized by impossible. According to Halliday(1985), the Relational process is the process of being indicating relations between two entities. Thus another entity has to be located. By the first analysis, it can be discovered that the circumstance in this clause can either be realized by without her contributions or by without her, thus forming the second analysis in the following:

\begin{tabular}{|c|c|c|c|}
\hline Without her & contributions & would be & impossible \\
\hline Circumstance & Carrier & Relational Process & Attribute \\
\hline
\end{tabular}

From this analysis, it can be discovered that the correct choice of the circumstance can have a better understanding of GPP

\section{Conclusion}

From the above analyses, it can be easily concluded that only by the correct location of verbs and the process, the correct choices of participants and circumstance can the GPP clause be provided with correct understanding, which can prove that SFL can be used as an approach to interpret GPP. This can also demonstrate that SFL is both a general linguistics theory and an Appliable Linguistics theory.

*This Paper is based on the "12th Five-Year Plan" research program in humanities and social scienc es "A Study of Textual GPP from the Functional, Pragmatic and Cognitive Perspectives”[NO. 2014 -181], conducted by Jilin Provincial Education Department.

\section{References:}

[1] Bever, T. G. 'The Cognitive Basis for Linguistic Structures' [A]. In J. R. Hayes (Ed.), Cognition and the Development of Language [C]. New York: Wiley, 1970, 279-362.

[2] Feng Zhiwei \& Xu Fuji. A Probe into GPP. [Z]. HNG Second Academic Conference, 2003.

[3] Fodor, J. D. \& Inoue, A. 1990. 'The diagnosis and Cure of Garden Paths' [J]. Journal of Psycholinguistic Research, 23, 407-434

[4] Frazier, L. 'Sentence Processing: A Tutorial Review' [A]. In M. Coltheart (Ed.), The Psychology of Reading, Attention and Performance XII [C] NJ: Lawrence Erlbaum Associates, 1987,

[5] Frazier, L. \& K. Rayner. 'Making and Correcting Errors During Sentence Comprehension: Eye Movements in the Analysis of Structurally Ambiguous Sentences' [J]. Cognitive Psychology, 1982(14), 178-210.

[6] Halliday, M.A.K. 'Language Structure and Language Function’ [A]. In John Lyons(ed). New Horizons in Linguistics [C]. Harmondsworth: Penguin Books. 1970: 140-165.

[7] Halliday, M.A.K. An Introduction to Functional Grammar [M]. London: Edward Arnold, 1985.

[8] Jiang Zukang. 'A Literature Review on GPP’ [J]. FLTRP, 2000(4).

[9] Pritchett, B. L. 'Garden Path Phenomena and Grammatical Basis of Language Processing' [J]. Language, 1988, 64(3), 539-576. 